\title{
Effectiveness of "Rajyoga Meditation":A Quasi-experimental study for holistic healing in cancer patients
}

\author{
Singh A. $\bowtie$, Sharma S. B., Rana, A., Amandeep, Kaur, A., Kaur, A., Rani, B., \\ Kaur, G.
}

Received: 25.12 .2020

Revised: 12.03.2021

Accepted: 29.03.2021

\begin{abstract}
Raj Yoga is one of the tested spiritual, holistic healing approaches nowadays used for every field for promoting selfesteem in healthy and unwell patients at mental and psychological levels. Cancer is one of the end-stage diseases that give not only physical pain but also causes psychological threats to the patient. The patient may experience grief, fear of death, loneliness, low self-esteem and other emotional changes resulting in depression and anxiety disorders. During this stage, some spiritual or holistic healing approaches are must for the enhanced wellbeing status of cancer patients, so the current study is focused on evaluating the effectiveness of Raj Yoga Meditation in cancer patients in selected hospital of Punjab In this study, the Raj Yoga Meditation programme was introduced for 15-20 minutes per day for six consecutive days to the experimental group. Although the study period was concise, however, the results showed that there was a significant difference between pre-test $(141.64 \pm 18.9624)$ and post-test $(167.400 \pm 23.0922)$ wellbeing scores at the 0.05 level of significance.
\end{abstract}

Key words: Cancer, Cancer Patients, Holistic Healing, Rajyoga Meditation

\section{Introduction}

"Raj yoga meditation helps the individual to return to a state of inner peace, personal power and selfworth through re-kindling the soul's original qualities and virtues which are effective for the overall wellbeing of individuals (Sain et al., 2020)

Chronic disease profile, especially Cancer, affects the patient physically, not only mentally, but also socially\& spiritually too. According to Indian population census data, the rate of mortality due to Cancer disease was high in India which includes the estimated number of 2.25 million people are living with this disease and every year approximate $11,57,2941$ lakh people do their registration as a new case and 7,84,8217 cancer-related deaths have also been reported on the basis of studies data depicted that $7.34 \%$ male\& $6.28 \%$ females are having the risk of dying from Cancer before the age of 75 years (Anonymous, 2020a).Cancer is one of the chronic diseases, which is the second leading cause of mortality estimated 9.6 million deaths in 2018 globally, and it has been reported that 1 in 6 deaths was due to Cancer.(Anonymous 2020b) Cancer

\section{Author's Address}

State Institute of Nursing and Paramedical Sciences, Badal, BFUHS Faridkot $(\mathrm{Pb})$, India

E-mail.: anjalisingh26july@gmail.com affects the patients physically, mentally, socially and spiritually. On the basis of Government survey report of Punjab depicts that Malwa region having the highest number of cancer patients which are approximate 107 in 100,000 populations. Four districts, i.e. Muktsar, Mansa, Bathinda and Ferozepur districts are on the top in cancer incidence list, which includes approximate 136 cancer cases per 100,000 people. There are multiple factors responsible for this disease; one of them that becomes a significant risk factor is chemical toxicity which covers the excessive level of arsenic and uranium \& use of pesticides. It has also been found that smoking \&consumption of alcohol also aggravates the risk of Cancer in malwa region (Anonymous 2020b). The Rajyoga is an inner approach like a mobile device to be used anywhere, anytime, unobtrusively as eternal technology just like an e-Health goal to reach everyone wherever he/she is, i.e. beyond the geographical terrain. Rajyoga meditation is an ancient system of medicine believed to harmonize spiritual, mental and physical energy which helps in enhancement of power to lead a stress-free life (Kiran et al., 2017) . With the help of meditation, an individual can 
experience a natural state of happiness by the development of soul's inner values\&powers which opens a pathway to true peace of mind. On the basis of studies, Raja means 'a King' and yog or Yoga means 'a connection or relationship'. Rajyoga is the highest form or Supreme yoga by practising \& by connecting with the supreme soul, the Soul becomes king or master of all senses (Anonymous 2020c). It has been found that long term spiritually focused meditation practice contributed to enhanced wellbeing and resilience for subjects in cancer diagnosis and further treatment challenges. It helps the cancer patients to bring awareness about seeing the self as soul and enhancement of spiritual energy by connecting with the supreme soul. Spiritual energy is distinct from the body, which is an important source of spiritual strength and growth for cancer survivors (Agarwal et al.,2020).In another study, it has been found that Rajyoga meditation helps to maintain a patient's biochemical and haematological profile during breast cancer treatment (Goyal et al.,2018) So Brahma Kumaris Rajyoga meditation technique revived by Rajyoga education and research foundation is scientifically proven not only for an enhanced quality of farm production but also for the wellbeing of farmers who practise this meditation (Sain et al., 2020).

Therefore based upon the Research studies \&reviews of Rajyoga meditation, personal experiences of the researcherand in-depth consultations withexperts of Rajyoga meditation encouraged the researcher to make an effort to conduct the research study on cancer patients So the current study is entitled "a quasi-experimental study to assess the effectiveness of Rajyoga meditation for holistic healing on wellbeing status among cancer patients at selected cancer hospitals of Punjab".

\section{Materials and Methods}

In this study, a quasi-experimental design with nonprobability convenient sampling technique was used with sample size 50 . The current study was conducted in Guru Gobind Singh Medical College and Hospital (GGSMCH) Faridkot, Punjab, India. The study was conducted in the day-care centre and cancer ward of GGSMCH, Faridkot. All the admitted patients who were willing to participate in the study were taken as study subjects. Rajyoga meditation was provided by the students who got trained \& certified by BrahmakumarisRajyoga meditation centre, Faridkot, Punjab, India. On the first day of study, pre interventional level of wellbeing status was assessed among subjects in the experimental and control group by using standardized Singh \& Gupta wellbeing scale.A structured Rajyoga meditation programme included the sessions, which consisted of knowledge and meditation sessions. The sessions were conducted with the help of lectures, audios (meditation music) and meditation commentary by students. Every day 25-30 minutes session was held by the trained students, i.e. 5-10 minutes devoted to meditation music and commentaries and 15-20 minutes were devoted to giving a lecture to the cancer patients.

In the quasi-experimental study design, 50 participants (25 in experimental and 25 in the control group) were selected by using a nonprobability convenient sampling technique. The study was approved by the ethical committee of the state institute of Nursing \&paramedical sciences Badal and informed consent was taken from each participant. Data were collected using standardized Singh and Gupta (2001) wellbeing scale. The tool consisted of three sections as under:

\section{Section A}

Part 1: Socio-demographic profile: It consisted of ten items as age, gender, religion, education, occupation, income, type of family, marital status, dependency status and dietary pattern.

Part 2: It consisted of 8 items which included medical diagnosis, stage of Cancer, present health problem and ongoing treatment, duration of continuing treatment, no of hospitalizations after being diagnosed, other continuous complementary therapy and other medical condition.

Section B: It consisted of planned Rajyoga meditation programme/Training- It had two parts.

Part A: The knowledge regarding Rajyoga. The sessions were conducted by lectures, audios (meditation music) and everyday meditation commentary.

Part B: Meditation session: The knowledge as in part A was followed by everyday meditation session 15-20 minutes with commentaries and audios (mediation music) by trained students. It included experiencing and realizing self as a soul, realizing and experiencing "supreme soul", 
connecting with the supreme soul to charge and rejuvenating them. The total time for meditation sessions was 25-30 minutes every day.

Section C: Singh and Gupta wellbeing scale (2001) A 50 items standardized scale to assess the effect of Rajyoga meditation in the subjects. The items were related to physical, mental, emotional, social and spiritual wellbeing. It consisted of 29 positive items and 21 negative items. All items to be scored on 5 points Likert scale from 1 to 5 with total 50-250 scores depending upon the responses of subjects.

\section{Results and Discussion}

As has been depicted in Table 4 and fig 1, while comparing, it was found that in the experimental group the pre-interventional mean $\pm \mathrm{SD}$ was $141.640 \pm 18.9624$ and the post interventional mean $\pm \mathrm{SD}$ was $167.400 \pm 23.0922, \mathrm{t}=16.257, \mathrm{df}=24$ was significant. On the other hand, in control group preinterventional mean \pm S.D. was $144.680 \pm 21.2127$ and post interventional mean \pm S.D. was $145.480 \pm 21.8806, \quad \mathrm{t}=2.889, \quad \mathrm{df}=24 \quad$ was nonsignificant. Hence, there was a significant

Table 1: Frequency and percentage distribution of cancer patients (experimental and control group) according to demographic variables

\begin{tabular}{|c|c|c|c|c|}
\hline \multirow{2}{*}{ Variables } & \multicolumn{2}{|c|}{ Experimental Group $\quad(n=25)$} & \multicolumn{2}{|c|}{ Control Group $(\mathrm{n}=25)$} \\
\hline & f & $\%$ & f & $\%$ \\
\hline \multirow{4}{*}{$\begin{array}{l}\text { 1.Age (in years) } \\
\text { a) } 20-35 \text { years } \\
\text { b) } 36-50 \text { years } \\
\text { c) } 51-65 \text { years } \\
\text { d) } 66-80 \text { years }\end{array}$} & 2 & $8 \%$ & 1 & $4 \%$ \\
\hline & 8 & $32 \%$ & 10 & $40 \%$ \\
\hline & 13 & $52 \%$ & 13 & $52 \%$ \\
\hline & 2 & $8 \%$ & 1 & $4 \%$ \\
\hline \multirow{2}{*}{$\begin{array}{l}\text { 2.Gender } \\
\text { a) Male } \\
\text { b) Female }\end{array}$} & 9 & $36 \%$ & 6 & $24 \%$ \\
\hline & 15 & $60 \%$ & 19 & $76 \%$ \\
\hline \multirow{4}{*}{$\begin{array}{l}\text { 3.Religion } \\
\text { a) Hindu } \\
\text { b) Muslim } \\
\text { c) Sikh } \\
\text { d) Christian }\end{array}$} & 6 & $24 \%$ & 5 & $20 \%$ \\
\hline & 0 & $0 \%$ & 1 & $4 \%$ \\
\hline & 19 & $76 \%$ & 19 & $76 \%$ \\
\hline & 0 & $0 \%$ & 0 & $0 \%$ \\
\hline \multirow{5}{*}{$\begin{array}{l}\text { 4. Education } \\
\text { a) Illiterate } \\
\text { b) Primary } \\
\text { c) Secondary } \\
\text { d) Senior secondary } \\
\text { e) Post graduation }\end{array}$} & 14 & $56 \%$ & 13 & $52 \%$ \\
\hline & 4 & $16 \%$ & 4 & $16 \%$ \\
\hline & 6 & $24 \%$ & 4 & $16 \%$ \\
\hline & 1 & $4 \%$ & 2 & $8 \%$ \\
\hline & 0 & $0 \%$ & 2 & $8 \%$ \\
\hline \multirow{5}{*}{$\begin{array}{l}\text { 5. Occupation } \\
\text { a) Agriculture } \\
\text { b) Housewife } \\
\text { c) Labourer } \\
\text { d) Private job } \\
\text { e) Govt. job }\end{array}$} & 1 & $4 \%$ & 2 & $8 \%$ \\
\hline & 15 & $60 \%$ & 17 & $68 \%$ \\
\hline & 3 & $12 \%$ & 2 & $8 \%$ \\
\hline & 5 & $20 \%$ & 4 & $16 \%$ \\
\hline & 1 & $4 \%$ & 0 & $0 \%$ \\
\hline \multirow{4}{*}{$\begin{array}{l}\text { 6. Income (per month in rupees) } \\
\text { a) Less than } 10,000 \\
\text { b } 10,001-20,000 \\
\text { c) } 20,001-30,000 \\
\text { d) more than } 30,000\end{array}$} & 15 & $60 \%$ & 9 & $36 \%$ \\
\hline & 7 & $28 \%$ & 10 & $40 \%$ \\
\hline & 0 & $0 \%$ & 4 & $16 \%$ \\
\hline & 3 & $12 \%$ & 2 & $8 \% 7$ \\
\hline \multirow{4}{*}{$\begin{array}{l}\text { 7. Marital status } \\
\text { a) Married } \\
\text { b) Unmarried } \\
\text { c) Widow/widower } \\
\text { d) Any other significant }\end{array}$} & 22 & $88 \%$ & 23 & $92 \%$ \\
\hline & 1 & $4 \%$ & 1 & $4 \%$ \\
\hline & 2 & $8 \%$ & 1 & $4 \%$ \\
\hline & 0 & $0 \%$ & 0 & $0 \%$ \\
\hline
\end{tabular}


Singh et al.

\begin{tabular}{|c|c|c|c|c|}
\hline \multirow{2}{*}{$\begin{array}{l}\text { 8. Dietary pattern } \\
\text { a) Vegetarian } \\
\text { b) Non- vegetarian }\end{array}$} & 16 & $64 \%$ & 21 & $84 \%$ \\
\hline & 9 & $36 \%$ & 4 & $16 \%$ \\
\hline \multirow{7}{*}{$\begin{array}{l}\text { 9.Medical diagnosis } \\
\text { a) Cancer of respiratory system } \\
\text { b) Cancer of reproductive system } \\
\text { c) Cancer of breast } \\
\text { d) Cancer of gastrointestinal system } \\
\text { e) Cancer of haematological system } \\
\text { f) Cancer of integumentary system } \\
\text { g) Cancer of lymphatic system }\end{array}$} & 3 & $12 \%$ & 2 & $8 \%$ \\
\hline & 10 & $40 \%$ & 8 & $32 \%$ \\
\hline & 3 & $12 \%$ & 4 & $16 \%$ \\
\hline & 7 & $28 \%$ & 7 & $28 \%$ \\
\hline & 1 & $4 \%$ & 0 & $0 \%$ \\
\hline & 0 & $0 \%$ & 3 & $12 \%$ \\
\hline & 1 & $4 \%$ & 1 & $4 \%$ \\
\hline \multirow{4}{*}{$\begin{array}{l}\text { 10. Ongoing complementary } \\
\text { therapy } \\
\text { a) Counselling } \\
\text { b) Yoga } \\
\text { c) Meditation } \\
\text { d) Not any }\end{array}$} & 0 & $0 \%$ & 0 & $0 \%$ \\
\hline & 1 & $4 \%$ & 1 & $4 \%$ \\
\hline & 6 & $24 \%$ & 6 & $24 \%$ \\
\hline & 18 & $72 \%$ & 18 & $72 \%$ \\
\hline
\end{tabular}

As per the socio-demographic profile $60 \%$ patients were females in the experimental group and $76 \%$ in the control group, majority and equal percentage belonged to Sikh religion, i.e. $76 \%$ in both groups, $60 \%$ subjects were housewives in the experimental group and $68 \%$ in the control group, $88 \%$ subjects were married in experimental, and $92 \%$ in the control group, $64 \%$ subjects were vegetarian in experimental and $84 \%$ in the control group. Ongoing complementary therapy was taken by $72 \%$ subjects in both groups.

Table 2: Mean and standard deviation of post interventional level of wellbeing status among cancer patients in the experimental and control group

\begin{tabular}{|l|l|l|}
\hline Group & Mean score & Standard deviation \\
\hline Experimental & 141.640 & 18.9624 \\
\hline Control & 144.680 & 21.2127 \\
\hline
\end{tabular}

Pre interventional mean score for the experimental group was found 141.640 and S.D. 18.9624, whereas pre interventional mean score for the control group was 144.680 and S.D. 21.2127

Table 3: Mean and standard deviation of pre interventional level of wellbeing status among cancer patients in the experimental and control group $(\mathrm{N}=50)$

\begin{tabular}{|l|l|l|}
\hline Group & Mean score & Standard deviation \\
\hline Experimental & 167.400 & 23.0922 \\
\hline Control & 145.480 & 21.8806 \\
\hline
\end{tabular}

Post interventional mean score for the experimental group was 167.400 and S.D. 23.0922, whereas post-intervention means score for the control group was 145.480 and S.D. 21.8806

Table 4: Comparison of pre and post interventional level of wellbeing status among cancer patients in the experimental and control group

\begin{tabular}{|c|c|c|c|c|c|c|c|c|}
\hline & \multicolumn{4}{|c|}{ Wellbeing Scores } & \multirow{2}{*}{\multicolumn{3}{|c|}{ Paired t test }} \\
\hline & & \multicolumn{2}{|c|}{ Pre test } & \multicolumn{2}{|l|}{ Post test } & & & \\
\hline Group & $\mathbf{N}$ & Mean & SD & Mean & SD & df & t test & Result \\
\hline Experimental & 25 & 141.640 & 18.9624 & 167.400 & 23.0922 & 24 & 16.257 & Significant \\
\hline Control & 25 & 144.680 & 21.2127 & 145.480 & 21.8806 & 24 & 2.889 & Non-significant \\
\hline \multirow{3}{*}{$\begin{array}{l}\text { Unpaired } \\
\text { t test }\end{array}$} & $\mathrm{df}$ & \multicolumn{2}{|l|}{48} & $\mathrm{df}$ & 48 & & & \\
\hline & T test & \multicolumn{2}{|c|}{-534} & T test & 3.445 & & & \\
\hline & Result & \multicolumn{2}{|c|}{ Non-significant } & Result & $\begin{array}{l}\text { Significan } \\
\mathrm{t}\end{array}$ & & & \\
\hline
\end{tabular}


difference between pre and post-interventionalwell-being status in the experimental group. Meditation is widely accepted as a beneficial health practice, and nowadays, many organizations offer training in meditation. Raja yoga is one of the known cost-effective methods and does not need a long time for the results. It is known as one of the highest of all teachings because it works on "self as soul" soul and a complementary method to practically prevent and manage physical, mental, social, emotional and spiritual problems. It is readily available feasible in almost all parts of the world. There are 8500 centres of Brahma kumaris in all over India and in $>140$ countries.

Although the literature is scarce regarding the effect of Rajyoga meditation on cancer patients. In the current study, results revealed that although the study period was significantly less. However the results showed that the wellbeing status of subjects significantly improved with interventions of Rajyoga meditation on the basis of study findings of one study $52 \%$ of subjects reported a high wellbeing status, $48 \%$ showed average wellbeing whereas none of the subjects reported in the category of a low level of wellbeing status. (Singh et al., 2019). In another quasi-experimental study (Singh et al., 2019) conducted on addicted patients with non-probability convenient sampling technique and 60 samples were taken. Theeffectiveness was evaluated by standardized Singh and Gupta wellbeing scale. A similar type of findings showed, i.e. statistically significant at the
0.05 level in the wellbeing status of the experimental group between pre-test (148.47 \pm $15.589)$ andpost-test $(178.20 \pm 18.983)$. Therefore, from the above findings, it can be concluded that Rajyoga meditation is effective in improving overall wellbeing status of subjects. (Singh et al., 2018). Secondly, in the current study, the experimental group showed that there was a significant difference between pre-test $(141.64 \pm 18.9624)$ and post-test $(167.400 \pm 23.0922)$ wellbeing scores at the 0.05 level of significance.

In a similar experimental study conducted by (Maini et al., 2011) highlighted the hemodynamic and the biochemical effects of Rajyoga meditation on the blood pressure, heart rate and ECG where 100 healthy people were selected from the Brahmakumaris Ashram, Amritsar. The subjects were categorized into two groups. Group-1included 50 subjects in the age groups of 25-50 years who were performing Rajyoga meditation regularly for at least one hour a day from last 2-5 years.Group-2 did not perform any meditation. The results showed a statistically significant mean value of heart rate in the meditator group, which was 69.39 \pm 5.26 , andit was $81.66 \pm 3.66$ in the non-meditator group.The results of systolic and diastolic blood pressure were also found significant $(p<0.001)$. The study concluded that Rajyoga had positive effects on the cardiovascular system and reduced the risk of developing cardiovascular diseases (Maini et al., 2011).

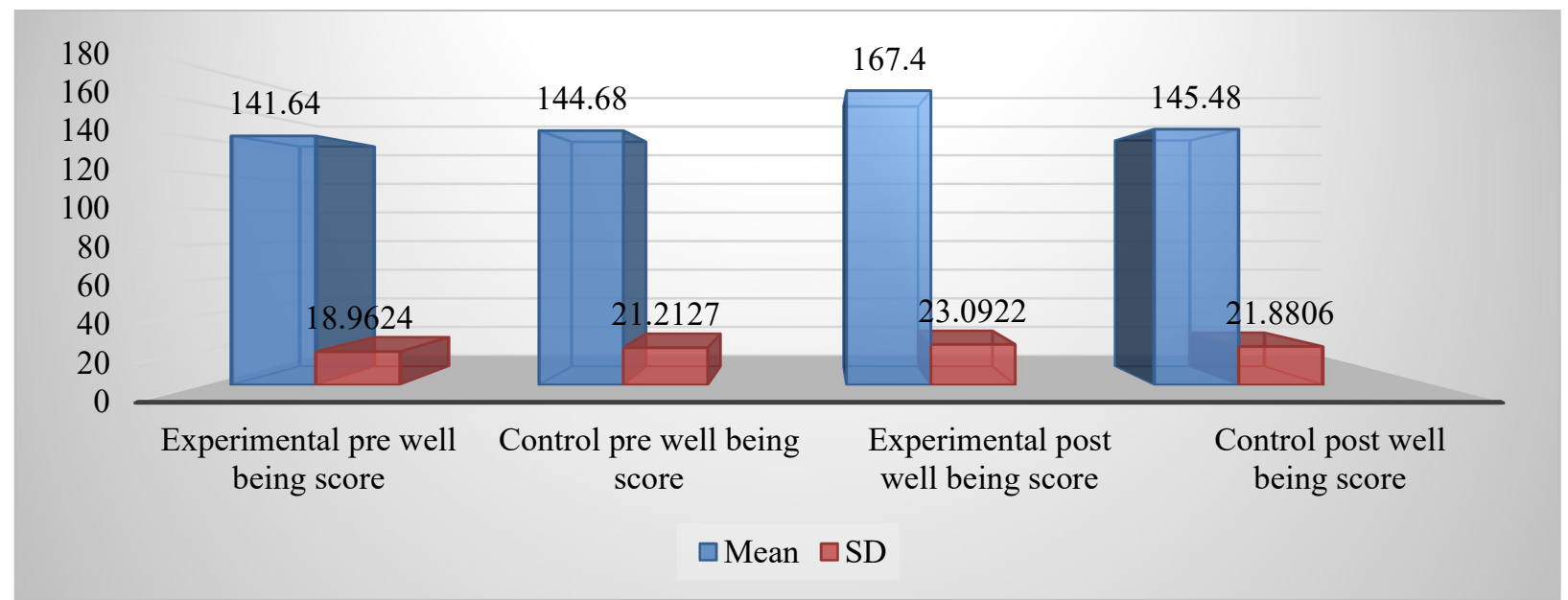

Figure 1: Comparison of pre and post interventional level of wellbeing among cancer patients in the experimental and control group (Bar diagram) 


\section{Conclusion}

Although the study period was concise, however, the results showed that there was a significant difference between pre-test (141.64 \pm 18.9624$)$ and post-test (167.400 \pm 23.0922$)$ wellbeing scores at the 0.05 level of significance.Although the primary study was limited to 50 samples, almost all the patients reported enhanced wellbeing and inner peace after the intervention. The study concluded that Rajyoga meditation is effective in the enhancement of wellbeing status of cancer patients.

\section{Future Scope of the Study}

- A sample size of the study, i.e. 50 cancer patients; hence it is difficult for broad generalization. Pilot and main study were conducted in the same setting due to pandemic COVID-19. It should be done on a large scale for broad generalization.

- The scope is not limited to a sample but is as broad as every human of the planet. Every individual, politician, health administrators etc. should be sanitized on a large scale for its importance.

- It is strongly recommended Rajyoga meditation must be implemented to each and every individual whether in all the professions, households to all age groups, hospitalized patients and their families as it is the most significant necessity of today when the whole global environment is stricken with Pandemic COVID-19 and fear and terrors all around the entire planet.

\section{Conflicts of interest}

The authors declare equal contribution and mutual consent with all the parts of the research. Also, no conflict of interest is there with any organization about the materials discussed in this manuscript.

\section{Acknowledgement}

All the expenses related to the research study were managed by the authors only. No fundings were received from any funding agency or society.

\section{References}

Agarwal, K., Fortune, L., Heintzman, J. C., \& Kelly, L. L. 2020. Spiritual experiences of long-term meditation practitioners diagnosed with breast cancer: an interpretative phenomenological analysis pilot study. Journal of religion and health, 1-17. $\begin{array}{lcc}\begin{array}{c}\text { Anonymous, } \\ \text { https://www.cancerindia.org.in/cancer-statistics// }\end{array} & \text { from }\end{array}$ (accessed on 25 October 2020).

Anonymous, 2020b. Down To Earth | Latest news, opinion, analysis on environment. Retrieved from https://www.downtoearth.org.in (accessed on 26 October 2020).

Anonymous, 2020c. Retrieved from www.brahmakumaris.com (accessed on 17 November 2020).

Goyal, A. K., Bakshi, J., Rani, S., Didi, B. A., \& Anand, A. 2018. Is Rajyoga helpful in maintaining patient's biochemical and hematological profile during breast cancer treatment?. Journal of Complementary and Integrative Medicine, 16(2).

Kiran, U., Ladha, S., Makhija, N., Kapoor, P. M., Choudhury, M., Das, S. \& Airan, B. 2017. The role of Rajyoga meditation for modulation of anxiety and serum cortisol in patients undergoing coronary artery bypass surgery: A prospective randomized control study. Annals of cardiac anaesthesia, 20(2), 158.

Maini, S., Kaur, H., \& Maini, N. 2011. Effect of Rajyoga meditation on the Heart Rate blood pressure and ECG. Journal of Clinical and Diagnostic Research, 5(8), 1519-1522.

Sain, M., Singh, A., Kaur, A., \& Zalpouri, R. 2020. Metaphysical energy based sustainable yogic farming for enhanced productivity and farmers' well being: A Review. Environment Conservation Journal, 21(3): 6368.

Singh,A.,Sharma,B.S.,Kaur,A.,Kumari,A.,Anju.,Rani,B.,Saini, D.,Kaur,G. 2019.Effectiveness of Rajyoga meditation for holistic healing in addicted patients: A quasi Experimental study. International Journal of Advanced Research and review. 11:64-67. 